\title{
Glucose-induced Microvascular Functional Changes in Nondiabetic Rats Are Stereospecific and Are Prevented by an Aldose Reductase Inhibitor
}

Joseph R. Williamson, Eva Ostrow, Donald Eades, Katherine Chang, Wanda Allison, Charles Kilo,* and William R. Sherman* Departments of Pathology, ${ }^{*}$ Internal Medicine, and ${ }^{\ddagger}$ Psychiatry, Washington University School of Medicine, St. Louis, Missouri 63110

\begin{abstract}
Exposure of skin chamber granulation tissue vessels in nondiabetic rats to 11 or $15 \mathrm{mM}$ D-glucose (but not L-glucose or 3-O-methylglucose) twice daily for $10 \mathrm{~d}$ induces vascular functional changes (increased albumin permeation and blood flow) identical to those in animals with mild or severe streptozotocin diabetes, respectively. These vascular changes are strongly linked to increased metabolism of glucose via the sorbitol pathway and are independent of nonenzymatic glycosylation as well as systemic metabolic and hormonal imbalances associated with the diabetic milieu. (J. Clin. Invest. 1990. 85:1167-1172.) diabetes $\bullet$ hormones $\bullet$ granulation tissue $\bullet$ angiogenesis $\bullet$ nonenzymatic glycosylation
\end{abstract}

\section{Introduction}

A growing body of evidence is consistent with the hypothesis that metabolic imbalances associated with hyperglycemia are of central importance in the pathogenesis of the late complications of diabetes $(1,2)$. On the other hand, multiple hormonal imbalances (in insulin levels, growth hormone, growth factors, catecholamines, sex steroids, thyroid hormone, etc.) associated with systemic hyperglycemia (and/or hypoglycemia) also have been postulated to play important roles in the pathogenesis of diabetic complications. A major obstacle to sorting out the role(s) and interactions of specific metabolic imbalances and hormonal factors in the pathogenesis of diabetic vascular complications has been the lack of animal models in which any one factor can be varied in vivo, independent of the others, and its effects on vascular function or structure quantified.

We have overcome this problem for vascular function by the use of a skin chamber granulation tissue model in which blood flow and vascular albumin permeation can be quantified in new (granulation tissue) vessels formed in bilateral (control and test) skin chambers in nondiabetic as well as in diabetic rats (3). Granulation tissue is a highly vascular connective tissue formed (in response to injury) by proliferating new vessels and fibroblasts with associated extracellular matrix constituents (including type I and type IV collagen, heparan sulfate proteoglycans, laminin, etc.), all of which have been shown to be biochemically or structurally altered in various

Address reprint requests to Dr. Williamson, Department of Pathology, Box 8118, Washington University School of Medicine, 660 South Euclid Avenue, St. Louis, MO 63110.

Received for publication 21 August 1989 and in revised form 28 November 1989.

J. Clin. Invest.

(c) The American Society for Clinical Investigation, Inc. 0021-9738/90/04/1167/06 \$2.00

Volume 85, April 1990, 1167-1172 tissues of diabetic humans and animals (2). In our view vascular complications of diabetes constitute a spectrum of (abnormal) vasoproliferative responses to injury ranging from simple thickening of capillary basement membranes and accumulation of extracellular matrix in many tissues to formation of complete new vessels in the eye (4). Although the association between vasoproliferative and vascular functional changes in human subjects with diabetic complications is well known, it remains unclear whether these phenomena are causally related.

Diabetic subjects with proliferative retinopathy, i.e., new vessels arising from the retina or optic disk, are the highest risk group for loss of vision caused by functional and structural abnormalities of these new vessels (5-7). These new vessels are very fragile, i.e., they tend to bleed spontaneously, and they leak fluorescein dyes much more profusely than nearby retinal vessels formed before the onset of diabetes $(8,9)$. Similarly vascular albumin permeation in diabetic rats is markedly increased in new (subcutaneous) granulation tissue vessels (induced by implanting fabric under the skin) formed in the diabetic milieu, but not in vessels of neighboring muscle or skin from which the new granulation tissue vessels are derived (10). In addition, vascular albumin permeation in these newly formed vessels is much more pronounced than that in vessels (present before induction of diabetes) in ocular tissues, peripheral nerve, kidney, and aorta (the most common sites of vascular complications in human diabetics) $(10,11)$. Thus, proliferating new granulation tissue vessels may be particularly useful for investigating the pathogenesis of vascular functional changes associated with diabetes. Two important advantages of the skin chamber model are that: $(a)$ during angiogenesis, new vessels in the test and control chambers can be exposed to synthetic media differing only in the concentration of a single component, i.e., substrate, hormone, or pharmacologic agent, and $(b)$ the newly formed granulation tissue vessels can be recovered for analysis free of contamination by adjacent tissue whose age and metabolic history are unknown. The amounts of reagents added to the chambers are so small that once they are absorbed into the blood they have no systemic effects.

In the present studies, we have assessed the effects of topically applied glucose on blood flow as well as on vascular albumin permeation in skin chamber granulation tissue vessels formed in nondiabetic male Sprague-Dawley rats.

\section{Methods}

\section{Chamber insertion and protocol for topical application of reagents}

A modification of the granulation tissue-skin chamber model utilized by Lundberg and Gerdin (3) was used for these studies. Very briefly, 2-cm circles of skin were removed from the back on either side of the midline (after shaving the hair) of normal Sprague-Dawley rats (weighing 250-300 g) that were anesthetized with sodium pentobarbi- 
tol $(35 \mathrm{mg} / \mathrm{kg}$ i.p.). The flanged base of the plastic chamber was then sutured to the skin at the margins of the wound with the skin overlapping the flange to prevent reepithelialization of the granulation tissue inside the chamber and separation of the chamber from the skin by regrowth of hair. New vessels and granulation tissue then form spontaneously on the surface of the exposed fascia inside the chambers. The chambers are equipped with stainless steel screwcaps which are readily removed to permit addition of metabolites, pharmacologic agents, etc. to the new vessels as they form inside the chamber.

Starting $10 \mathrm{~d}$ after insertion of the chambers, $0.5 \mathrm{ml}$ of PBS or Hepes buffer containing penicillin-G $(100 \mu \mathrm{g} / \mathrm{ml})$ and gentamycin $(10$ $\mu \mathrm{g} / \mathrm{ml}$ ), in addition to one or more of the following reagents, is added to each chamber: (a) 5, 8, 11, 15, or $30 \mathrm{mM}$ D-glucose or L-glucose (a nonmetabolizable stereoisomer of D-glucose that penetrates cells much more slowly than D-glucose since its uptake is not facilitated by glucose transporters), (b) $30 \mathrm{mM}$ 3-O-methylglucose (a nonmetabolizable analogue of D-glucose that is transported into cells at rates similar to those for D-glucose by the same glucose transporters), or (c) $30 \mathrm{mM}$ D-glucose plus $0.07 \mathrm{mM}$ tolrestat ( $N$-[[5-(trifluoromethyl)-6-methoxy-1naphthalenyl]-thioxomethyl]- $N$-methylglycine), an inhibitor of aldose reductase. These solutions were added two times daily (9:00 AM and 5:00 PM) for $10 \mathrm{~d}$ to the chambers. 2-10 d after initiating treatment with these solutions (and 30-60 min after the last treatment), blood flow and vascular permeation by radiolabeled albumin were quantified as described below.

\section{Protocol for assessment of vascular albumin permeation and blood flow}

After $10 \mathrm{~d}$ of topical glucose applications, rats were anesthetized with Inactin (Byk Gulden, Konstanz, West Germany) $(100 \mathrm{mg} / \mathrm{kg}$ body wt i.p.) and the left femoral vein and both iliac arteries were cannulated with polyethylene tubing filled with heparanized saline. The femoral vein cannula was used for tracer injection, the right iliac artery cannula was connected to a pressure transducer (P50; Statham Instruments, Inc., Oxnard, CA) for monitoring blood pressure as well as for arterial blood sampling, and the left iliac artery cannula was connected to a withdrawal pump for assessment of regional blood flow. The trachea also was cannulated and connected to a small rodent respirator for continuous ventilatory support.

Preparation of radiolabeled tracers. ${ }^{125}$ I-BSA and ${ }^{131}$ I-BSA were prepared by iodinating $20 \mathrm{mg}$ of purified monomer BSA with $1 \mathrm{mCi}$ of ${ }^{125}$ I or ${ }^{131}$ I (NEN Research Products, Boston, MA) by the lactoperoxidase method (12) and rat erythrocytes were chromated as described previously (13).

Assessment of albumin permeation. Two different methods were used to assess vascular permeation by radiolabeled albumin. The first method (utilized for the initial experiments) was a double-isotope ratio technique, which provides an index of vascular albumin permeation that permits assessment of changes in permeation associated with experimental interventions, but does not provide quantitative plasma clearance data. The index of vascular albumin permeation obtained by this method is the tissue-to-blood isotope ratio (TBIR) ${ }^{1}$, which is obtained by dividing the ratio of ${ }^{125} \mathrm{I}-\mathrm{BSA} /{ }^{51} \mathrm{Cr}-\mathrm{RBC}$ counts in the tissue by the corresponding ratio of counts in arterial blood obtained at the time the animal is killed (11). A TBIR $>1$ is indicative of permeation of the vasculature by albumin into the extravascular space. With this method, ${ }^{51} \mathrm{Cr}-\mathrm{RBC}(1 \mathrm{ml}$ of $40 \% \mathrm{Hct}$ rat $\mathrm{RBC}$ in PBS) were injected through a femoral vein cannula $5 \mathrm{~min}$ before time 0 . At time $0{ }^{125} \mathrm{I}$ BSA (in $0.3 \mathrm{ml}$ of PBS) was injected through the femoral vein cannula. 10 min after injection of ${ }^{125} \mathrm{I}-\mathrm{BSA}$, an arterial blood sample $(0.2 \mathrm{ml})$ was obtained; the chest cage was then immediately opened, the heart was excised, and granulation tissue was removed from the chambers for quantification of tracer content and for polyol analysis.

The second method for assessment of vascular albumin perme-

1. Abbreviations used in this paper: TBIR, tissue to blood isotope ratio; TMS, trimethylsilyl. ation utilized two different radiolabeled albumins $\left({ }^{131} I\right.$ and $\left.{ }^{125} I\right)(14)$. ${ }^{131}$ I-BSA was the primary (or permeating) tracer and was allowed to circulate for $10 \mathrm{~min}$. ${ }^{125} \mathrm{I}$-BSA was used as the intravascular space tracer (to correct tissue ${ }^{131} \mathrm{I}-\mathrm{BSA}$ activity for intravascular tracer as described below) $(15,16)$ and was allowed to circulate for only 2 min (assuming that relatively little tracer permeates the vasculature during this time, note correction for this assumption below). At time $0{ }^{131} \mathrm{I}-\mathrm{BSA}$ (in 0.3 $\mathrm{ml}$ of PBS) was injected through the femoral vein catheter. 8 min later ${ }^{125}$ I-BSA (in $0.3 \mathrm{ml}$ PBS) was injected through the same catheter. In order to obtain a time-averaged plasma activity of ${ }^{131} \mathrm{I}-\mathrm{BSA}, \mathrm{a} 0.2-\mathrm{ml}$ blood sample was taken from the right iliac artery cannula at 1,5 , and 10 min after 0 time. Immediately after each arterial withdrawal an equal volume of saline was injected intravenously. $10 \mathrm{~min}$ after injection of ${ }^{131}$ I-BSA the experiment was terminated and granulation tissue was removed from the chambers for quantification of tracer content by gamma spectrometry and for polyol analysis.

${ }^{131}$ I-BSA activity in the tissue was corrected for tracer contained within vessels by multiplying ${ }^{125}$ I-BSA activity in the tissue by the ratio of ${ }^{131} \mathrm{I}-\mathrm{BSA} /{ }^{125} \mathrm{I}$-BSA activities in the arterial blood sample obtained at the end of the experiment. The vascular-corrected ${ }^{131}$ I-BSA activity (i.e., extravascular tracer) was then divided by the time-averaged ${ }^{131} \mathrm{I}$ BSA plasma activity (calculated from the blood samples obtained at 1 , 5 , and $10 \mathrm{~min}$ after tracer injection) and by the tracer circulation time (10 $\mathrm{min})$ and normalized per gram tissue wet weight. This clearance value for ${ }^{131} \mathrm{I}$-BSA is then multiplied by 1.2 to provide an approximate correction for permeation of the intravascular reference tracer ${ }^{125} \mathrm{I}$ BSA) during its 2-min circulation time. The $1.2 \times$ correction factor is based on the assumption that ${ }^{125}$ I-BSA permeates the vasculature at the same rate as the primary tracer which circulates for $10 \mathrm{~min}$. Vascular clearance of plasma ${ }^{131} \mathrm{I}-\mathrm{BSA}$ is expressed as $\mu \mathrm{l}$ plasma.g wet weight $^{-1} \cdot \min ^{-1}$.

Estimates of vascular clearance of plasma ${ }^{131}$ I-BSA calculated in this manner are relatively free of potentially confounding effects of differences in hematocrit, plasma volume, or tracer distribution volume of tissues exposed to different glucose solutions. Because blood flow is higher in tissues exposed to $30 \mathrm{mM}$ D-glucose than to those exposed to $5 \mathrm{mM}$ D-glucose, equilibration of the intravascular reference tracer will tend to occur more rapidly in the tissues exposed to higher glucose levels. Thus any putative error in estimation of vascular clearance of plasma ${ }^{131}$ I-BSA due to incomplete mixing of the intravascular tracer will tend to obscure or reduce (rather than artifactually increase) differences in albumin clearance in tissues exposed to $5 \mathrm{vs.} 30$ $\mathrm{mM}$ glucose.

Assessment of blood flow. Blood flow (expressed as $\mathrm{ml} \mathrm{blood} \cdot \mathrm{g}$ wet weight ${ }^{-1} \cdot \mathrm{min}^{-1}$ ) was measured by injecting $15 \mu \mathrm{m}^{85} \mathrm{Sr}$-microspheres (NEN Research Products) as described in previous publications (14, 17). Animals were prepared in the same manner as for assessment of albumin permeation except that the chest wall was opened to expose the heart for microsphere injection. When blood pressure had stabilized $(\approx 10 \mathrm{~min})$ a withdrawal pump attached to an iliac artery was started at $0.34 \mathrm{ml} / \mathrm{min}$ and microspheres were injected over a $10-15-\mathrm{s}$ interval into the left ventricular chamber. The withdrawal pump was stopped $90 \mathrm{~s}$ later, the heart was excised, and granulation tissue was sampled. ${ }^{85} \mathrm{Sr}$ activity in the tissue and in blood from the withdrawal pump were quantified in a gamma spectrometer.

\section{Time-course of change in skin chamber glucose concentration after addition of $15 \mathrm{mM}$ D-glucose}

After addition of $0.5 \mathrm{ml}$ of $15 \mathrm{mM}$ D-glucose to a chamber, $10 \mu \mathrm{l}$ aliquots of chamber fluid were removed at 0 time and at intervals of 5 , $10,20,30 \mathrm{~min}$, etc. for measurement of glucose concentration by the hexokinase method (18). In addition, a blood sample was obtained before addition of glucose to the chamber for determination of plasma glucose levels.

\section{Measurement of tissue polyol levels}

Chemical ionization gas chromatography/mass spectrometry with ammonia as reagent gas and helium as carrier gas was used to measure 
tissue polyols as their trimethylsilyl (TMS) derivatives (19). TMS derivatives of sorbitol, mannitol, and galactitol are not separated by this procedure; however, in rats fed standard rat chow and in tissues exposed to glucose, the major tissue polyol was presumed to be sorbitol.

\section{Statistics}

Differences between groups were assessed by Students' $t$ test (two tailed); differences within groups were assessed by the paired $t$ test. Data are expressed as mean \pm SEM.

\section{Results}

Vascular albumin permeation was markedly increased in granulation tissue exposed to 11,15 , and $30 \mathrm{mM}$ D-glucose (Table I), but not by $8 \mathrm{mM}$ D-glucose, compared with tissues exposed to corresponding concentrations of L-glucose. In addition, albumin permeation in tissues exposed to $15 \mathrm{mM}$ Dglucose was significantly higher than in those exposed to 11 mM D-glucose $(P<0.001)$ but did not differ from that of tissues exposed to $30 \mathrm{mM}$ D-glucose. Indices of albumin permeation in tissues exposed to $8 \mathrm{mM}$ D-glucose and to $8,11,15$,

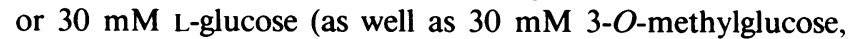
data not shown) were identical to values in tissues exposed to buffer alone. Granulation tissue clearance of plasma ${ }^{131}$ I-BSA is increased approximately fourfold by $30 \mathrm{mM}$ D-glucose (Fig. $1 \mathrm{~A}$ ). Approximately $50 \%$ of this increase is evident after $2-5 \mathrm{~d}$ of glucose applications (data not shown).

Blood flow in tissues exposed to $30 \mathrm{mM}$ D-glucose was increased by $70 \%$ relative to that of tissues exposed to $5 \mathrm{mM}$ D-glucose (Fig. $1 \mathrm{~B}$ ). Blood flow was increased by $43 \%$ ( $P$ $<0.001)$ in tissues exposed to $15 \mathrm{mM}$ D- versus those exposed to L-glucose in the contralateral control chamber (data not shown).

Table I. Effects of D-vs. L-Glucose on Vascular Albumin Permeation

\begin{tabular}{rccc}
\hline & \multicolumn{2}{c}{ Vascular albumin permeation } & \\
\cline { 2 - 3 } & L-Glucose & D-Glucose & $\Delta$ VAP \\
\hline $8 \mathrm{mM}$ & $2.38 \pm 0.04$ & $2.41 \pm 0.06$ & $0.03 \pm 0.02$ \\
$11 \mathrm{mM}$ & $2.39 \pm 0.03$ & $3.10 \pm 0.11$ & $0.71 \pm 0.04^{*}$ \\
$15 \mathrm{mM}$ & $2.50 \pm 0.07$ & $3.63 \pm 0.10$ & $1.13 \pm 0.03^{*}$ \\
$30 \mathrm{mM}$ & $2.38 \pm 0.04$ & $3.60 \pm 0.05$ & $1.22 \pm 0.02^{*}$
\end{tabular}

${ }^{*} P<0.001$ (paired $t$ test).

Stereospecificity of glucose effects on vascular albumin permeation. Granulation tissue formation was_induced in bilateral skin chambers in nondiabetic $\approx 250$-g male Sprague-Dawley rats by removal of 2 $\mathrm{cm}$ circles of skin on either side of the midline of the back. Beginning $10 \mathrm{~d}$ later, $0.5 \mathrm{ml}$ of $8(n=6), 11(n=9), 15(n=9)$, or 30 $(n=9) \mathrm{mM}$ D-glucose in PBS containing penicillin-G $(100 \mu \mathrm{g} / \mathrm{ml})$ and gentamycin $(10 \mu \mathrm{g} / \mathrm{ml})$ was added to the test chamber twice daily. The contralateral control chamber in each animal received an equal volume of PBS containing the same concentration of L-glucose. After $10 \mathrm{~d}$ of topical glucose application, rats were anesthetized with Inactin and vascular permeation by ${ }^{125}$ I-BSA was assessed by a double-isotope ratio method using ${ }^{51} \mathrm{Cr}$-rat $\mathrm{RBC}$ as a vascular space marker. The index of vascular albumin permeation, the tissue-toblood isotope ratio, is obtained from the formula: ${ }^{125} \mathrm{I} /{ }^{51} \mathrm{Cr}$-tissue $\div{ }^{125} \mathrm{I} /{ }^{51} \mathrm{Cr}$-blood. Values shown are mean \pm SEM. See text for details.
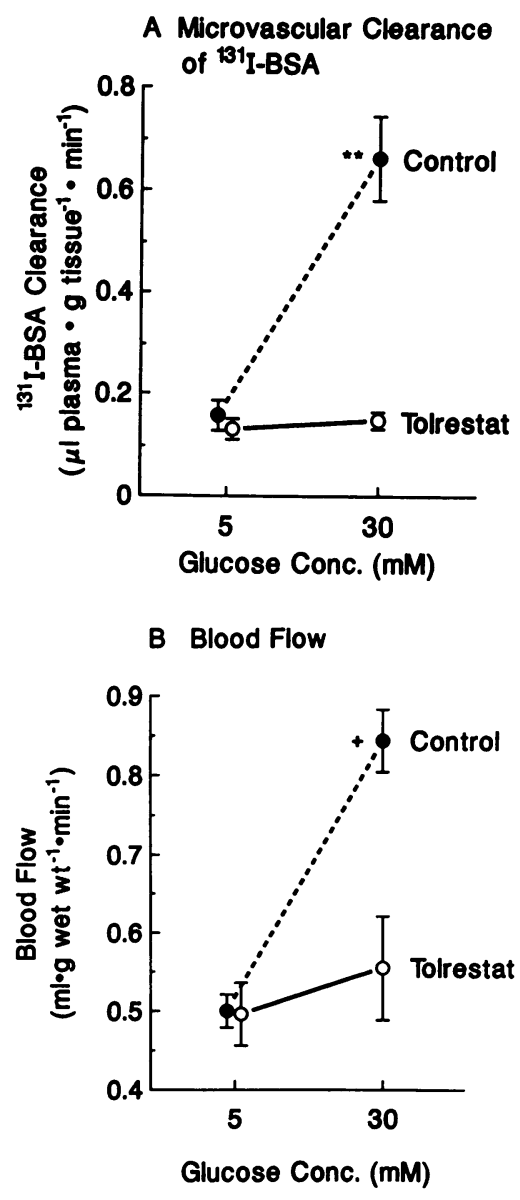

\section{Sorbitol Content}

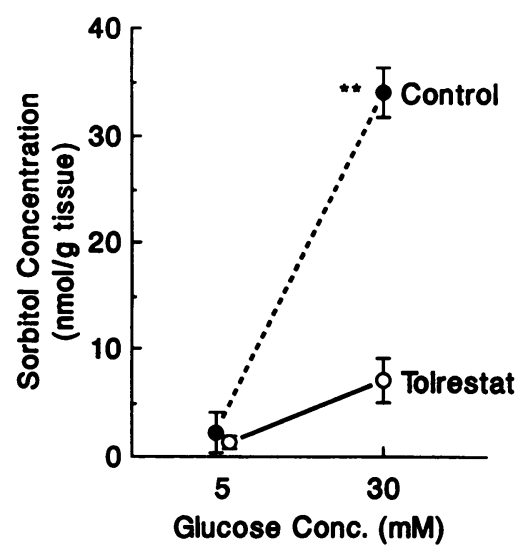

Figure 1. Effects of an inhibitor of aldose reductase (Tolrestat) on $30 \mathrm{mM}$ D-glucose-induced increases in vascular clearance of plasma ${ }^{131} \mathrm{I}$-BSA, blood flow, and sorbitol content of granulation tissue. Skin chamber granulation tissue was induced as described in the legend to Table I. PBS buffer $(0.5 \mathrm{ml})$ containing 5 or $30 \mathrm{mM}$ D-glucose $\pm 0.07 \mathrm{mM}$ tolrestat was added to the chambers two times daily for $10 \mathrm{~d} .{ }^{131}$ I-BSA clearance $(A)$ was assessed after a tracer circulation time of $10 \mathrm{~min}$ with subtraction of intravascular tracer content based on plasma levels of ${ }^{125}$ I-BSA (after a tracer circulation time of $2 \mathrm{~min}$ ). Blood flow $(B)$ was estimated by injection of $15 \mu \mathrm{M}^{85} \mathrm{Sr}$ microspheres. Sorbitol levels $(C)$ were assessed by GC/MS as their trimethylsilyl derivatives. Values shown are mean $\pm \operatorname{SEM}(n \geq 7)$ for each group except for blood flow in $5 \mathrm{mM}$ glucose $+0.07 \mathrm{mM}$ tolrestat, $n=3$. $^{* *}$ Significantly different from all other groups, $P$ $<0.001$; ${ }^{+}$significantly different from all other groups, $P \leq 0.005$. See text for details.

Sorbitol levels were increased over 10 -fold in tissues exposed to $30 \mathrm{mM}$ vs. those exposed to $5 \mathrm{mM}$ D-glucose (Fig. 1 $C$ ). The demonstration of this increase in tissue sorbitol levels was critically dependent on sampling the tissues within 30-60 min after the last application of glucose to the chamber. No increase in sorbitol levels was demonstrable in tissues removed 2-3 $\mathrm{h}$ after the last glucose application (data not shown). In contrast, demonstration of increases in vascular albumin permeation and blood flow was insensitive to the interval between glucose application and assessment of vascular function.

Tolrestat (at a concentration of $0.07 \mathrm{mM}$ ) completely pre- 
vented $30 \mathrm{mM}$ D-glucose-induced increases in granulation tissue albumin clearance, blood flow, and sorbitol levels (Fig. 1).

After addition of $0.5 \mathrm{ml}$ of $15 \mathrm{mM}$ D-glucose to a chamber, glucose levels in chamber fluid rapidly decrease and fall to plasma glucose levels by $\approx 150 \mathrm{~min}$ (Fig. 2).

\section{Discussion}

These observations indicate that elevation of skin-chamber granulation tissue glucose levels increases blood flow and vascular albumin permeation, independent of metabolic and hormonal imbalances associated with systemic hyperglycemia, to levels observed in subcutaneous granulation tissue in rats with streptozotocin diabetes $(11,20)$. This important finding supports the hypothesis that early vascular functional changes associated with diabetes are largely the consequence of hyperglycemia per se. These observations and conclusions are consistent with reports that acute elevations in plasma glucose levels in humans and in experimental animals are associated with hemodynamic changes in the eyes and kidneys (21-23). At the same time, they are consistent with evidence that the onset and progression of diabetic vascular complications are modulated by a variety of other risk factors including hormones and blood pressure $(2,24-26)$.

The increases in albumin permeation in tissues subjected to $11 \mathrm{mM}$ D-glucose are identical to those in fabric-induced, subcutaneous granulation tissue in rats with very mild streptozotocin-induced diabetes (11) and demonstrate that plasma glucose levels commonly observed in human diabetics are associated with vascular functional changes in the animal model. The increases in albumin permeation in tissues exposed to 15 and $30 \mathrm{mM}$ D-glucose correspond to those in rats with severe streptozotocin diabetes with plasma glucose levels ranging from 24 to $31 \mathrm{mM}$ D-glucose $(11,19,20)$. The finding that the increase in vascular clearance of radiolabeled albumin produced by $15 \mathrm{mM}$ D-glucose is almost as marked as that with 30 $\mathrm{mM}$ D-glucose suggests that near maximal diabetes-induced endothelial injury is produced by glucose levels between 11 and $15 \mathrm{mM}$ D-glucose. These observations and interpretations are consistent with evidence that the ratio of increased vascular albumin permeation per unit increase in plasma glucose levels in subcutaneous granulation tissue (as well as in ocular tissues, nerve, kidney, and aorta) is higher in rats with very mild than in those with overt streptozotocin diabetes (27).

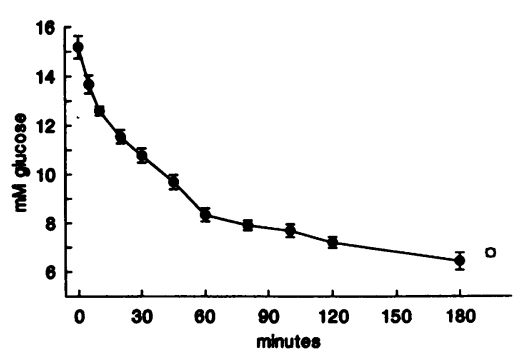

Figure 2. Time-course of change in skin chamber glucose concentration after addition of $15 \mathrm{mM}$ D-glucose. Skin chambers were mounted on normal male rats as described in the legend to Table I. After addition of $0.5 \mathrm{ml}$ of $15 \mathrm{mM} \mathrm{D}$ -

glucose to a chamber, 10- $\mu \mathrm{l}$ aliquots of chamber fluid were removed at 0 time and at intervals of $5,10,20,30 \mathrm{~min}$, etc. for measurement of glucose concentration. Plasma glucose levels before addition of glucose to the chamber are shown at the far right (open circle).

Values shown are mean $\pm \operatorname{SEM}(n=4)$.
The $43 \%$ increase in blood flow induced by $15 \mathrm{mM}$ D-glucose is consistent with $25-35 \%$ increases in (subcutaneous) granulation tissue blood flow in rats with severe streptozotocin-induced diabetes of 4-6 wk duration (20, unpublished observations). The somewhat higher blood flow induced by 30 $\mathrm{mM}$ D-glucose than in granulation tissue of diabetic rats may be related to differences in duration and severity of glycemia. Since the vasculature of tissues exposed to $5 \mathrm{vs}$. $30 \mathrm{mM}$ D-glucose or to D- vs. L-glucose in the test and control chambers is subject to the same arterial blood pressure, increased blood flow in tissues exposed to elevated D-glucose levels must reflect dilation of resistance arterioles or increased vascularity of the tissue. Increased vascularity is unlikely since blood volumes (reflected by granulation tissue content of ${ }^{51} \mathrm{Cr}-\mathrm{RBC}$ ) were identical in tissues treated with $15 \mathrm{mM}$ D- and L-glucose $(0.015 \pm 0.001 \mathrm{SEM}$ vs. $0.016 \pm 0.001 \mathrm{ml}$ of blood/g tissue). It is noteworthy in this regard that in studies of granulation tissue induced by fabric implanted subcutaneously, blood volume and collagen accumulation per milligram of implanted fabric also were identical in control and diabetic rats (28).

These observations and interpretations are consistent with diabetes-induced increases in blood flow (in the absence of angiogenesis) in ocular tissues, peripheral nerve, and kidney in rats with diabetes of 4-6 wk duration in which mean arterial blood pressure is identical to that of control rats (20). They also are consistent with morphological evidence that intestinal arterioles are dilated in rats given twice-daily intraperitoneal injections of $16.6 \mathrm{mM}$ glucose ( $5 \%$ body weight) for a duration of 4-5 wk (29). Thus we conclude that glucose-induced increases in blood flow in this model are the consequence of a decrease in arteriolar resistance, i.e., possibly due to impaired contractile function of smooth muscle cells in resistance arterioles. An important consequence of decreased arteriolar resistance is that arterial blood pressure will be transmitted further downstream into the microvasculature producing microvascular hypertension which has been postulated to contribute to the pathogenesis of diabetic microangiopathy $(2,20,30,31)$.

The finding that glucose levels in chamber fluid rapidly decrease and fall to plasma glucose levels within $150 \mathrm{~min}$ indicates that even transient elevations in tissue glucose levels occurring only two times daily are associated with impairment of vascular function. This observation is consistent with the morphological evidence cited above of vasodilation in intestinal arterioles following twice daily intraperitoneal injections of glucose (29) and with evidence that rats with very mild streptozotocin diabetes (with normal fasting plasma glucose levels but with elevated glycosylated hemoglobin levels and, by implication, postprandial hyperglycemia) develop vascular functional changes that are disproportionately large (relative to the minimal increase in glycemia and tissue polyol levels) compared with those in rats with overt diabetes, although they develop more slowly $(11,27)$. Plasma glucose levels do not change after addition of $15 \mathrm{mM}$ glucose to the chamber since only $0.13 \mathrm{mg}$ of glucose is lost from the chamber during the first $5 \mathrm{~min}$ and the rate of glucose loss diminishes thereafter. If this amount of glucose $(0.13 \mathrm{mg})$ were injected intravenously (as a bolus) into rats with a body weight of $300 \mathrm{~g}$, and with a blood volume of $15 \mathrm{ml}$ ( $5 \%$ of body weight), mean blood glucose would be transiently elevated by only $\approx 0.05 \mathrm{mM}(0.9$ $\mathrm{mg} / \mathrm{dl})$.

The demonstration that tolrestat, at a concentration of $0.07 \mathrm{mM}$, completely prevented $30 \mathrm{mM}$ D-glucose-induced 
increases in vascular albumin clearance, blood flow, and sorbitol levels (Fig. 1) is consistent with evidence from numerous studies indicating that vascular functional changes (increases in albumin permeation, blood flow, glomerular filtration rate, and urinary albumin excretion) in rats with streptozotocin diabetes are linked to increased metabolism of glucose by the sorbitol pathway and are prevented by a variety of structurally different chemical inhibitors of the enzyme aldose reductase, which also prevent diabetes-induced increases in tissue sorbitol levels without affecting plasma glucose levels $(2,11,20)$.

The absence of an effect of tolrestat on vascular albumin permeation, blood flow, and sorbitol levels in tissues exposed to $5 \mathrm{mM}$ D-glucose is consistent with minimal effects of aldose reductase inhibitors in general on tissue function and sorbitol levels in normal rats.

The likelihood that these vascular functional changes induced by topical glucose are independent of nonenzymatic glycosylation is supported by evidence that: $(a)$ tolrestat and other inhibitors of aldose reductase which prevent vascular changes associated with diabetes have no effect on blood glucose levels or nonenzymatic glycosylation of proteins $(11,20)$, and $(b)$ L-glucose had no effect on vascular function even though it is capable of nonenzymatic glycosylation (i.e., of hemoglobin) analogous to that observed with D-glucose (Lorenzi, M., personal communication). In addition, it appears unlikely that these vascular functional changes are linked to increased synthesis of diacylglycerol and associated alterations in protein kinase $C$ activity since the latter changes are not prevented by inhibitors of aldose reductase (32-34). On the other hand, both nonenzymatic glycosylation $(35,36)$ and other glucose-induced metabolic imbalances (32-34) may contribute to end-stage diabetic vascular disease.

While the present studies do not provide any insights regarding the cellular mechanisms that mediate glucose-induced increases in vascular albumin clearance, observations from other investigations suggest that the increased clearance is largely the consequence of impaired endothelial cell barrier function (11,20, unpublished observations). They do not, however, exclude a possible contribution by increased hydraulic conductance related to increased blood flow and microvascular hypertension $(30,31)$.

It is noteworthy that increased vascular albumin permeation in granulation tissue of diabetic rats is both prevented and reversed during euglycemia following islet transplantation (28) and infusion of insulin by pumps (37). The slow relatively linear rate of normalization of vascular albumin permeation over $14 \mathrm{~d}$ (despite normalization of plasma glucose and sorbitol levels within $2 \mathrm{~d}$ by insulin pumps [37]) suggests that increased vascular albumin permeation induced by hyperglycemia is the consequence of slowly reversible biochemical and/ or structural alterations in the vasculature rather than to immediate, rapidly reversible alterations in endothelial cell barrier function analogous to those produced by vasoactive agents such as histamine $(13,38)$. This view is also consistent with the finding that vascular functional changes were still demonstrable 2-3 $\mathrm{h}$ after the last glucose application (despite normalization of tissue sorbitol levels) and evidence that glucose-induced increases in granulation tissue vascular albumin permeation continued to increase between 5 and $10 \mathrm{~d}$ of exposure to $30 \mathrm{mM}$ D-glucose.

Although the precise nature of the aldose reductase-linked metabolic imbalance that mediates vascular functional abnor- malities induced by glucose remains unclear, it is of interest that exposure of tissue chamber granulation tissue to $1 \mathrm{mM}$ sorbitol induces vascular functional changes (39) identical to those produced by 15-30 mM D-glucose. In addition, vascular functional changes induced by both $30 \mathrm{mM}$ D-glucose and by $1 \mathrm{mM}$ sorbitol are prevented by the inclusion of 1-3 mM pyruvate $(39,40)$. These observations, coupled with those of Travis et al. (41), suggest that vascular functional changes induced by glucose (and by sorbitol) may be linked to metabolic imbalances associated with a reduction in the ratio of $\mathrm{NAD}^{+}$/ NADH (caused by increased oxidation of sorbitol to fructose).

Conclusions. These observations and interpretations support the hypothesis that early microvascular functional changes in diabetic humans and animals are: $(a)$ primarily the consequence of hyperglycemia per se, independent of the multiple systemic metabolic and hormonal imbalances associated with the diabetic milieu, and $(b)$ mediated by, or strongly linked to, increased metabolism of glucose via the sorbitol pathway.

\section{Acknowledgments}

We thank Dr. C. Lundberg for generously providing us with skin chambers for pilot studies and for his advice and suggestions regarding the use of skin chambers and measurement of blood flow. We thank Mrs. Ann Stone for preparation of the manuscript.

This research was supported by National Institutes of Health grants HL-39934, EY 06600, and DK-20579 and by the Kilo Diabetes and Vascular Research Foundation. Tolrestat was provided by Ayerst Laboratories Research, Inc., New York.

\section{References}

1. Winegrad, A. I. 1987. Does a common mechanism induce the diverse complications of diabetes? Diabetes. 36:396-406.

2. Williamson, J. R., R. G. Tilton, K. Chang, and C. Kilo. 1988. Basement membrane abnormalities in diabetes mellitus. Relationship to clinical microangiopathy. Diabetes/Metab. Rev. 4:339-370.

3. Lundberg, C., and B. Gerdin. 1984. The inflammatory reaction in an experimental model of open wounds in the rat. The effect of arachidonic acid metabolites. Eur. J. Pharmacol. 97:229-238.

4. Williamson, J. R., and C. Kilo. 1980. Vascular complications in diabetes mellitus. N. Engl. J. Med. 302:399-460.

5. Vision Research-A National Plan (1983-1987). Vol. 2, Part 1, NIH Publication No. 83-2471.p. 71

6. Aeillo, L. M., L. I. Rand, J. G. Sebestyen, J. N. Weiss, M. I. Bradbury, M. Z. Wafai, and J. C. Briones. 1985. The eyes and diabetes. In Joslin's Diabetes Mellitus. 12th ed. A. Marble, L. P. Krall, R. F. Bradley, A. R. Christlieb, J. S. Soeldner, editors. Lea \& Febiger, Philadelphia. 600-634.

7. Davis, M. D. 1988. Diabetic retinopathy: A clinical overview. Diabetes/Metab. Rev. 4:291-322.

8. Norton, E. W. D., and F. Gutman. 1965. Diabetic retinopathy studied by fluorescein angiopgraphy. Ophthalmologica. 150:5-17.

9. Kohner, E. M., C. T. Dollery, J. W. Paterson, and N. W. Oakley. 1967. Arterial fluorescein studies in diabetic retinopathy. Diabetes. 16:1-10.

10. Kilzer, P., K. Chang, J. Marvel, E. Rowold, P. Jaudes, S. Ullensvang, C. Kilo, and J. R. Williamson. 1985. Albumin permeation of new vessels is increased in diabetic rats. Diabetes. 34:333-336.

11. Williamson, J. R., K. Chang, R. G. Tilton, C. Prater, J. Jeffrey, C. Weigel, W. R. Sherman, D. M. Eades, and C. Kilo. 1987. Increased vascular permeability in spontaneously diabetic $B B / W$ rats and in rats with mild versus severe streptozotocin-induced diabetes. Prevention by aldose reductase inhibitors and castration. Diabetes. 36:813-821. 
12. Krohn, K. A., and M. J. Welch. 1974. Studies of radioiodinated fibrinogen. I. Lactoperoxidase iodination of fibrinogen and comdel compounds. Int. J. Appl. Radiat. Isot. 25:315-323.

13. Kilzer, P., K. Chang, J. Marvel, C. Kilo, and J. R. Williamson. 1985. Tissue differences in vascular permeability changes induced by histamine. Microvasc. Res. 30:270-285.

14. Williamson, J. R., S. W. Holmberg, K. Chang, J. Marvel, S. P. Sutera, and P. Needleman. 1989. Mechanisms underlying atriopeptininduced increases in hematocrit and vascular permeation in rats. Circ. Res. 64:890-899.

15. Haraldsson, B., L. Regner, R. Hultborn, L. Weiss, and B. Rippe. 1984. Transcapillary passage of albumin in mammary tumours and in normal lactating mammary glands of the rat. Acta Physiol. Scand. 122:497-505.

16. Renkin, E. M., M. Gustafson-Sgro, and L. Sibley. 1988. Coupling of albumin flux to volume flow in skin and muscles of anesthetized rats. Am. J. Physiol. 255:H458-H466.

17. Tilton, R. G., G. Pugliese, K. Chang, C. Kilo, and J. R. Williamson. 1989. Effects of hypothyroidism on vascular ${ }^{125} \mathrm{I}$-albumin permeation and blood flow in rats. Metab. Clin. Exp. 38:471-478.

18. Lowry, O. H., and J. V. Passonneau. 1972. A Flexible System of Enzymatic Analysis. Academic Press, Orlando, FL. 174.

19. Williamson, J. R., E. Rowold, K. Chang, J. Marvel, M. Tomlinson, W. R. Sherman, K. E. Ackermann, R. A. Berger, and C. Kilo. 1986. Sex steroid dependency of diabetes-induced changes in polyol metabolism, vascular permeability, and collagen cross-linking. Diabetes. 35:20-27.

20. Tilton, R. G., K. Chang, G. Pugliese, D. M. Eades, M. A. Province, W. R. Sherman, C. Kilo, and J. R. Williamson. 1989. Prevention of hemodynamic and vascular albumin filtration changes in diabetic rats by aldose reductase inhibitors. Diabetes. 38:1258-1270.

21. Atherton A., D. W. Hill, H. Keen, S. Young, and E. J. Edwards. 1980. The effect of acute hyperglycaemia on the retinal circulation of the normal cat. Diabetologia. 18:233-237.

22. Christiansen, S. J., M. Frandsen, and H.-H. Parving. 1981. Effect of intravenous glucose infusion on renal function in normal man and in insulin-dependent diabetics. Diabetologia. 21:368-373.

23. Ernest, J. T., T. K. Goldstick, and R. L. Engerman. 1983. Hyperglycemia impairs retinal oxygen autoregulation in normal and diabetic dogs. Invest. Ophthalmol. Vis. Sci. 24:985-989.

24. Kohner, E. M., and P. S. Sharp. 1987. Diabetic retinopathy. In The Diabetes Annual/3. K. G. M. M. Alberti and L. P. Krall, editors. Elsevier Science Publishers, Amsterdam. 252-288.

25. Mogensen, C. E. 1987. Early diabetic renal involvement and nephropathy: can treatment modalities by predicted from identification of risk factors? In The Diabetes Annual/3. K. G. M. M. Alberti and L. P. Krall, editors. Elsevier Science Publishers, Amsterdam. 306-324.

26. Viberti, G. 1988. Recent advances in understanding mechanisms and natural history of diabetic renal disease. Diabetes Care. 11(Suppl. 1):3-9.
27. Pugliese, G., R. G. Tilton, A. Speedy, K. Chang, E. Santarelli, M. A. Province, D. Eades, W. R. Sherman, and J. R. Williamson. 1989. Effects of very mild versus overt diabetes on vascular hemodynamics and barrier function in rats. Diabetologia. 32:845-857.

28. Williamson, J. R., K. Chang, E. Rowold, C. Kilo, and P. E. Lacy. 1986. Islet transplants in diabetic Lewis rats prevent and reverse diabetes-induced increases in vascular permeability and prevent but do not reverse collagen solubility changes. Diabetologia. 29:392-396.

29. Bohlen, H. G., and K. D. Hankins. 1982. Early arteriolar and capillary changes in streptozotocin-induced diabetic rats and intraperitoneal hyperglycaemic rats. Diabetologia. 22:344-348.

30. Parving, H.-H., G. C. Viberti, H. Keen, J. S. Christiansen, and N. A. Lassen. 1983. Hemodynamic factors in the genesis of diabetic microangiopathy. Metab. Clin. Exp. 32:943-949.

31. Zatz, R., and B. M. Brenner. 1986. Pathogenesis of diabetic microangiopathy: the hemodynamic view. Am. J. Med. 80:443-453.

32. Lee, T.-S., L. C. MacGregor, S. J. Fluharty, and G. L. King. 1989. Differential regulation of protein kinase $\mathrm{C}$ and $(\mathrm{Na}, \mathrm{K})$-adenosine triphosphatase activities by elevated glucose levels in retinal capillary endothelial cells. J. Clin. Invest. 83:90-94.

33. Craven, P. A., and F. R. DeRubertis. 1989. Protein kinase $C$ is activated in glomeruli from streptozotocin diabetic rats. Possible mediation by glucose. J. Clin. Invest. 83:1667-1675.

34. Lee, T.-S., K. A. Saltsman, H. Ohashi, and G. L. King. 1989. Activation of protein kinase $\mathrm{C}$ by elevated glucose concentration: proposal for a mechanism in the development of diabetic vascular complications. Proc. Natl. Acad. Sci. USA. 86:5141-5145.

35. Kennedy, L., and J. W. Baynes. 1984. Non-enzymatic glycosylation and the chronic complications of diabetes: an overview. Diabetologia. 26:93-98.

36. Brownlee, M., H. Vlassara, A. Kooney, P. Ulrich, and A. Cerami. 1986. Aminoguanidine prevents diabetes-induced arterial wall protein cross-linking. Science (Wash. DC). 232:1629-1632.

37. Rogers, D., E. Rowold, K. Chang, M. Tomlinson, W. R. Sherman, J. Gavin, C. Kilo, and J. R. Williamson. 1988. Effect of rapid normalization of plasma glucose levels on microvascular dysfunction and polyol metabolism in diabetic rats. Diabetes. 37:1689-1694.

38. Majno, G., and G. E. Palade. 1961. Studies on inflammation. I. The effect of histamine and serotonin on vascular permeability: an electron microscopic study. J. Biophys. Biochem. Cytol. 11:571-605.

39. Williamson, J. R., K. Chang, E. Ostrow, W. Allison, J. Harlow, and C. Kilo. 1989. Sorbitol-induced increases in vascular albumin clearance (VAC) are prevented by pyruvate but not myo-inositol. Diabetes. 38(Suppl. 2):94A.

40. Williamson, J. R., K. Chang, E. Ostrow, V. Timm, and W. Allison. 1988. Normalization of D-glucose-induced increases in blood flow (BF) and ${ }^{125} \mathrm{I}$-albumin permeation (IAP) by myo-inositol (MI) and by pyruvate. Diabetes. 37(Suppl. 1):95A.

41. Travis, S. F., A. D. Morrison, R. S. Clements, Jr., A. I. Winegrad, and F. A. Oski. 1971. Metabolic alterations in the human erythrocyte produced by increases in glucose concentration: the role of the polyol pathway. J. Clin. Invest. 50:2104-2112. 